\title{
Los indicios de la actitud en las interacciones orales en el aula universitaria
}

\author{
Indicators of Attitude in Oral Interactions \\ in the University Classroom
}

\author{
Clarena Muñoz-Dagua ${ }^{1}$ \\ Martha Cecilia Andrade-Calderón² \\ Mireya Cisneros-Estupiñán ${ }^{3}$
}

\section{Resumen}

En este artículo se presentan los resultados del análisis hecho a grabaciones audiovisuales de las exposiciones realizadas por estudiantes de primeros semestres sobre un tema de ciencia. El marco general para la investigación es la Lingüística Sistémico-Funcional como modelo propicio para trabajar las interacciones y el discurso en su contexto de producción. De manera particular, con el concurso de la Teoría de la Valoración, se analizan los recursos que eligen los estudiantes para conseguir la explicación, mantener el contacto con el auditorio, negociar un espacio de diálogo en el aula de clases y fortalecer el discurso académico. Los resultados del análisis permiten, por un lado, visualizar la función que cumple la inscripción de la Actitud en la explicación de las temáticas, con los subsistemas de Afecto, Juicio y Apreciación y, por otro, advertir la importancia de diseñar estrategias didácticas que coadyuven al estudiante a seleccionar y depurar los mecanismos explicativos, graduar el contacto con el público y generar confianza para dar fuerza a su discurso.

\section{Palabras claves}

Sistema de Actitud, Teoría de la Valoración, Didáctica Crítica, Oralidad

\section{Abstract}

This article presents the results of the analysis of the presentations made by students of first semester from two universities on a science topic. The overall framework for the research is Systemic Functional Linguistics as a model conducive to work and interactions discourse in their context of production. Based on the Appraisal Theory, we analyze the resources that students choose to obtain the explanation, maintain contact with the audience, negotiate a space for dialogue in the classroom and strengthen academic speech. The results of the analysis allow us, on one hand, to get an insight of the role the registration of attitude in the explanation of the issues, with the subsystems of Affection, Appreciation and Judgment, and, on the other hand, to be aware of the importance of designing teaching strategies that help students to select and refine the explanatory mechanisms, regulate their contact with the public and build trust to enforce their speech.

\section{Key words}

Attitude system, theory of valuation, critical teaching, orality.

Artículo recibido el 7 de junio de 2014 y aprobado el 7 de abril de 2015

1 Universidad Colegio Mayor de Cundinamarca, Bogotá, Colombia. Correo electrónico: clargui@yahoo.es

2 Universidad Colegio Mayor de Cundinamarca, Bogotá, Colombia. Correo electrónico: marceanca@yahoo.es

3 Universidad Tecnológica de Pereira, Pereira, Colombia. Correo electrónico: mireyace@gmail.com 
La oralidad, entendida como medio de transferencia de información y contacto interpersonal, se constituye en el ámbito escolar en un eje desde el cual se expresa, amplía, confronta, reelabora y desarrolla el conocimiento. En efecto, aunque esta habilidad comunicativa, con frecuencia, es considerada como fácil de desempeñar debido a que es rutinaria, sencilla y cotidiana del ser humano, cuando se analiza a la luz de los contextos educativos, la perspectiva de valoración cambia. La oralidad es decisiva para asimilar, confrontar y reelaborar el discurso académico y, en la universidad, la construcción de un discurso académico sólido, que visibilice una educación de calidad, requiere revisar y avanzar en el análisis de los hábitos y actitudes que asumen los estudiantes en sus intervenciones orales como parte de su proceso de acceso, comprensión e interpretación de las competencias propias de su formación disciplinar. Así mismo, para la presentación pública de los trabajos académicos, de los avances de investigación y demás exposiciones, no solo se necesita tener solvencia y consistencia intelectual en el desarrollo del tema (Cisneros-Estupiñán 2012, p. 142); también es indispensable el manejo de otros elementos que no son propios del texto escrito sino de la oralidad, como por ejemplo, la seguridad, la claridad en la expresión, el uso adecuado de la lengua oral, el respeto, la cordialidad con los asistentes, etc.

Nuestro proyecto tiene su punto de partida, precisamente, en el reconocimiento de la necesidad de profundizar en el estudio de la oralidad en el nivel universitario, como una competencia fundamental que debe desarrollarse a la par con las habilidades de lectura y escritura. En otros espacios (Andrade, M. y Muñoz-Dagua, C. (2004)), hemos reivindicado la necesidad de investigar, dentro de los actuales contextos educativos, no solo las dificultades para leer y para escribir de los estudiantes, sino también los problemas para expresarse con fluidez y adecuación en exposiciones, disertaciones e intervenciones en las aulas de clase y demás escenarios académicos.

En este contexto, en el marco de la Lingüística Sistémico-Funcional, desarrollamos una investigación de carácter exploratorio, que retoma la Teoría de la Valoración (Martín, 2000), para analizar e interpretar las manifestaciones orales que se dan en el aula universitaria, con el fin de construir una metodología para evaluarlas, detectar dificultades y plantear estrategias de interacción que mejoren y enriquezcan los procesos discursivos en este espacio educativo. El artículo es un avance del proyecto "La oralidad en el aula universitaria. Una propuesta didáctica discursiva”, que actualmente se adelanta en dos universidades colombianas: Universidad Colegio Mayor de Cundinamarca (Bogotá) y Universidad Tecnológica de Pereira (Pereira).

El análisis se basa en veinte grabaciones de exposiciones realizadas por estudiantes de las facultades de Administración y Economía, y de Ingeniería, en las cuales se identifican las dificultades que presentan para conseguir la explicación, mantener el contacto con el auditorio y negociar un espacio de diálogo en el aula de clases. Algunos indicios recurrentes en la evaluación del problema se concentran en la falta de planeación del discurso, la transmisión incoherente y desorganizada de mensajes, el uso de barbarismos, las dificultades para acompañar la expresión verbal con lenguajes gestuales y corporales adecuados, las falencias cognitivas y semánticas cuando se trata de puntualizar conceptos, entre otros.

En la exposición, primero, hacemos referencia a la oralidad y sus peculiaridades en el orden lingüístico y textual en el discurso académico; en segundo lugar, reivindicamos la importancia de la Teoría de la Valoración (Martin, 2000) como un procedimiento metodológico oportuno para descubrir los problemas que se presentan en las interacciones orales en el aula de clase y proponer mecanismos tendientes a mejorar las prácticas discursivas. En tercer lugar, se presenta la ficha de registro con ejemplos de la inscripción de la Actitud, con los subsistemas de Afecto, Juicio y Apreciación en las exposiciones de los estudiantes.

\section{La palabra hablada}

Los textos que producen, intercambian o reciben los hablantes como unidad de sentido en uso, pueden presentarse de forma oral o escrita. En términos generales, se podría inferir que las diferencias entre el habla y la escritura se reducen a la sustancia uti- 
lizada para la expresión: sonido y figuras visuales, respectivamente. Sin embargo, cuando comparamos la apertura de una intervención de un estudiante en clase del tipo: "Ehhh... bueno, pues yooo voy hablar pues de lo de la lectura del ajedrez", difícilmente se puede admitir un inicio de este tipo en una construcción escrita. Este ejemplo supone que además de la sustancia existe una adecuación de la forma, es decir, de la elección de las palabras y las estructuras gramaticales para conseguir los objetivos propuestos en la comunicación. Luego, el medio, la forma y la función son elementos que, de acuerdo con Halliday (1994), se encuentran intrínsecamente unidos en la producción de textos orales y escritos.

Tanto la oralidad como la escritura conllevan distinciones desde el punto de vista lingüístico y textual: la atención y concentración de los sentidos en una y otra dependen no solo de lo que se quiere comunicar sino también del contexto situacional, esto es, todo acto de habla se da en unas condiciones diacrónicas (tiempo), diastráticas (culto-inculto), diafásicas (formal-informal) y diatópicas (argot-jerga), las cuales son relevantes para la interacción y la comprensión de los mensajes que se intercambian entre los hablantes. Aquí es importante aclarar que las circunstancias espacio-temporales no solo se reducen a los condicionamientos del tiempo actual (sincronía) sino que incluye la temporalidad histórica (diacronía).
Así, las propiedades de los discursos orales y escritos están determinadas por factores pragmáticos como el grado de conocimiento mutuo entre los interlocutores, las relaciones de simetría o asimetría frente al saber, el propósito de la interacción, la participación emocional, entre otros. Para el caso del discurso oral, que manifiesta las ideas, opiniones, sentimientos de una persona mediante la palabra hablada, el orador elige recursos como la descripción, la exposición, la narración y la argumentación para enfocar el tema, en correspondencia con la finalidad de su mensaje: informativa, explicativa o persuasiva.

En cuanto a las circunstancias, el discurso y los mecanismos utilizados para la interacción dependen del carácter de la relación entre los interlocutores, si es de confianza, por ejemplo, se genera un uso de la lengua de tipo informal mientras que si es de asimetría como sucede en las interacciones entre profesores y estudiantes se cambia hacia la formalidad. Este último caso es el que nos interesa analizar, esto es, el discurso que se produce en el ámbito académico, representado en charlas, exposiciones, intervenciones orales y disertaciones, orientadas a la formación profesional.

En términos generales, a continuación se puede apreciar las diferencias entre la escritura y la oralidad, en el marco académico.

Tabla 1. El discurso oral y el discurso escrito

\begin{tabular}{|c|c|c|}
\hline Propiedades & Oralidad & Escritura \\
\hline Pragmáticas & $\begin{array}{l}\text { Inmediatez comunicativa en: } \\
\text { Simultaneidad entre emisión-recepción del mensaje. } \\
\text { Simultaneidad temporal y espacial de los interlocutores. } \\
\text { Espontaneidad. } \\
\text { Planificación mínima. } \\
\text { Conocimiento mutuo de los interlocutores, } \\
\text { Saber compartido } \\
\text { Cotidianidad (vivencias compartidas como estudiantes) } \\
\text { En síntesis, en la oralidad se produce un discurso en ac- } \\
\text { ción, por tanto, más interactivo, espontáneo e informal. }\end{array}$ & $\begin{array}{l}\text { No implica simultaneidad en: } \\
\text { Emisión y recepción del mensaje } \\
\text { Co-presencia física de los interlocutores } \\
\text { Durabilidad } \\
\text { Planificación pertinente (formatos específicos) } \\
\text { El conocimiento entre interlocutores no es nece- } \\
\text { sario, las emociones y el mundo de la cultura se } \\
\text { explican mediante referencia a situaciones, fechas, } \\
\text { autores y cita de otras voces. } \\
\text { En síntesis en la escritura se produce un discurso } \\
\text { más formal, más reflexivo, menos interactivo, por } \\
\text { tanto, más cuidado en la expresión. }\end{array}$ \\
\hline
\end{tabular}


Universidad Pedagógica Nacional

Facultad de Humanidades

\begin{tabular}{|c|c|c|}
\hline Propiedades & Oralidad & Escritura \\
\hline \multirow[t]{2}{*}{ Lingüísticas } & $\begin{array}{l}\text { Referencias a elementos explícitos de la realidad, me- } \\
\text { diante el uso marcas deícticas extralingüísticas (aquí, } \\
\text { allí, ahora, este, aquel) }\end{array}$ & $\begin{array}{l}\text { Referencias a tiempo y espacio explícitas en el } \\
\text { texto. }\end{array}$ \\
\hline & $\begin{array}{l}\text { En síntesis, en el discurso oral se da una estructura } \\
\text { dinámica, densidad léxica baja y una gramática no es- } \\
\text { tándar, por tanto, compleja. }\end{array}$ & $\begin{array}{l}\text { En síntesis, en el discurso escrito se presenta una } \\
\text { estructura sinóptica, léxico especializado, densi- } \\
\text { dad léxica alta y una gramática estándar, por tanto, } \\
\text { simple. }\end{array}$ \\
\hline Paralingüísticas & $\begin{array}{l}\text { Uso de códigos kinésicos, prosódicos y proxémicos. } \\
\text { Énfasis en la participación emocional, fortalecimiento } \\
\text { del diálogo, la cooperación y solidaridad entre los parti- } \\
\text { cipantes y refuerzo al contacto con el auditorio }\end{array}$ & $\begin{array}{l}\text { Uso de signos de puntuación. } \\
\text { Uso de mecanismos como metáforas, recursos } \\
\text { interpersonales de modo y modalidad para la pre- } \\
\text { sentación del discurso y el acercamiento al lector. }\end{array}$ \\
\hline
\end{tabular}

En concordancia con estas particularidades de la oralidad, en las interacciones concretas de los estudiantes en la universidad es posible encontrar características en los planos fónico, morfosintáctico y léxico que dan cuenta del grado del lenguaje en acción, espontáneo, interactivo e informal. A partir de las transcripciones hechas a 20 exposiciones de estudiantes de diferentes carreras, acerca del texto "El ajedrez persa" de Carl Sagan (1998), ${ }^{4}$ seleccionamos algunos ejemplos para ilustrar las peculiaridades que presenta el discurso oral.

En el nivel fónico, se observan alargamientos recurrentes de sílabas (visirrrr, teeeexto, coooommooo, bueeennoo, aaasí, eeeste, quee, loooo, sooobreee, yyyy); pérdida o adición de sonidos en la pronunciación de las palabras (anticoncetivo, ovio, ...tonces, pa'que... masomeno), manejo de recursos de entonación para dar énfasis a ciertas partes de la exposición con pronunciación marcada y exclamaciones (mu-y tris-te; jvamos!) y sonidos paralingüísticos como (ahhhh..., ehhh..., ummmmm..., já..., psss...).

En el plano morfosintáctico, los estudiantes utilizan conectores pragmáticos del tipo ¿sigo así?, ¿sí?, ¿quee? bueno, pues, claro, entonces, o sea... intensificadores (estoy nervioso, ya terminé) o atenuantes

4 En la Universidad Colegio Mayor de Cundinamarca, los estudiantes pertenecen a la carrera de Tecnología en Asistencia Gerencial de la Facultad de Administración y Economía, y en la Universidad Tecnológica de Pereira pertenecen a Ingeniería Eléctrica y Licenciatura en Español y Literatura. (qué triste). Por su parte en el nivel léxico se perciben modismos y expresiones hechas y lenguaje coloquial (era muy jarto... haber... pues muchos ya han hablado que las matemáticas porque las utilizamooss todos los días bla bla bla... quisiera empezar hablando...).

En el plano textual, se encuentra la desorganización de las partes del discurso, la cual se evidencia en la ausencia de conectores que articulen la apertura, el desarrollo y el cierre, fundamentada en una gramática no estándar, compleja y con baja densidad léxica. De este modo, en las exposiciones se presentan cambios frecuentes de tema, presencia de rodeos explicativos, reelaboraciones (digo, bueno, o sea, haber...) y autocorrecciones (perdón, matemáti, ma-te-má-ticas...), alto grado de redundancia (ehhh... y el rey... el rey y el visir...ambos pues...), repeticiones, falta de concordancia y ausencia de marcas gramaticales, sencillez en la construcción de las oraciones y en el manejo del léxico.

Este tipo de hallazgos en el discurso oral de los estudiantes, aparte de ser indicativos de las propiedades que le corresponden a la lengua hablada, permiten justificar la necesidad de replantear el lugar del discurso oral, de tipo académico, en el aula universitaria. Consideramos que más allá de los errores de dicción causados en algunos casos por el nerviosismo y la falta de experiencia en la presentación frente al público, las transcripciones de las grabaciones muestran que la oralidad debería ser una competencia por desarrollar a la par con la escritura 
y la lectura en la universidad. Los supuestos que subyacen acerca de enfatizar en el texto escrito en la enseñanza superior, ha llevado, de alguna manera, a considerar la oralidad como una habilidad que no requiere ser estructurada, delineada y refinada pues el habla es connatural a los seres humanos.

De allí que en el marco del proyecto "La oralidad en el aula universitaria. Una propuesta didáctico discursiva", que actualmente desarrollamos desde el grupo de Estudios del Lenguaje y la Educación conformado por investigadores de la Universidad Colegio Mayor de Cundinamarca y la Universidad Tecnológica de Pereira en Colombia, nos hemos propuesto rescatar la oralidad como una competencia fundamental que la universidad debe fomentar para el desarrollo de las habilidades lingüísticas y comunicativas que le permitan al futuro profesional construir su propio discurso. La comunicación oral es una condición básica de la vida laboral contemporánea: saber hablar, saber intervenir en una reunión, hacer una ponencia, preguntar de manera adecuada, debatir una idea, presentar un argumento, dar una entrevista de trabajo, exigen una preparación en el contexto de la formación universitaria (MuñozDagua, Andrade y Cisneros-Estupiñán, 2011).

En este sentido, considerar que el estudiante tiene las competencias disciplinares y socioculturales suficientes para salir al mundo laboral supone el conocimiento de los instrumentos retóricos para asumir posturas frente al contenido experiencial de sus exposiciones, juicios y propuestas, hacia sus interlocutores y hacia la heteroglosia del contexto intertextual en el cual actúan. En otras palabras, cuentan con las habilidades discursivas necesarias para integrar de manera adecuada, medio, forma y función y, sobre la base de sus propósitos comunicacionales, conseguir credibilidad, integridad y eficacia en la consecución de los objetivos en juego en el contexto situacional.

Hoy, cuando las tecnologías de la información y la comunicación invaden nuestra cotidianidad y a veces nos dejan sin el sonido de la palabra (MuñozDagua, 2014), más que en otra etapa, se necesita rescatar la oralidad como forma primaria de memo- ria del pensamiento y de la civilización; ya Walter Ong en su clásico Oralidad y escritura (1982/1993) explicó cómo con la primera tecnología de la palabra el hombre fue capaz de reconstruir su historia y mantener la sociedad, el vínculo y la comunicación con sus congéneres. A ese reto le apuntamos con nuestro proyecto.

\section{La función interpersonal y la teoría de la valoración}

El modelo que asumimos para el análisis de la oralidad en el aula universitaria es el de la Lingüística Sistémico Funcional (Halliday, 1994), en particular, los desarrollos de la metafunción interpersonal, con la Teoría de la Valoración y sus categorías de Actitud, Compromiso y Gradación (Martín, 2000). Tal como se ha expresado, a partir de las propiedades del discurso oral, este implica el uso de una serie de recursos que comprometen la presencia reiterativa de formas evaluativas que expresan la actitud del orador frente a sus proposiciones y propuestas.

El énfasis sobre el carácter dialógico de la comunicación humana y el reconocimiento de los mecanismos que utilizan los hablantes para expresar sus actitudes y dar fuerza, énfasis y credibilidad a sus mensajes, hacen de la teoría de la Valoración una herramienta teórica y metodológica práctica y eficaz para analizar los mecanismos utilizados por estudiantes y docentes para la construcción de su discurso y proponer una estrategia didáctica que, desde las cátedras de comunicación y talleres de lectura y escritura, coadyuve a mejorar las prácticas discursivas orales en el aula universitaria.

En el marco de la Lingüística SistémicoFuncional (LSF), la Teoría de la Valoración (White, 2005 describe y explica los recursos lingüísticos que utilizan los hablantes para expresar, negociar y naturalizar determinadas posiciones intersubjetivas que son, en última instancia, ideológicas. Esta apertura hacia la exploración de los mecanismos lingüísticos que expresan la presencia de sentimientos y actitudes en los discursos permite evidenciar los fines retóricos que llevan a los hablantes a asumir posturas frente al contenido experiencial de sus enunciados, 
hacia sus interlocutores y hacia la heteroglosia del contexto intertextual en el que operan sus textos.

Para el análisis textual, la Teoría de la Valoración, de acuerdo con White (2005) se ocupa de los recursos léxico-gramaticales, de Actitud, Compromiso y Gradación utilizados en los discursos en contextos específicos. El primer Sistema de Actitud, alude a los valores que los hablantes comunican en sus juicios y las respuestas emocionales y afectivas que asocian a los participantes y los procesos con los sistemas de valores culturalmente determinados. La Actitud abarca tres regiones semánticas: la emoción, la ética y la estética, que se identifican respectivamente con los subsistemas de Afecto, Juicio y Apreciación. El Afecto caracteriza los fenómenos en relación con las emociones, el Juicio describe el comportamiento humano en correspondencia con el conjunto de normas sociales y hace referencia a la evaluación moral de la conducta, y la Apreciación se encarga de la evaluación de objetos y productos en relación con principios estéticos y otros sistemas de valor social.

El Sistema de Compromiso incluye los recursos por medio de los cuales la voz textual se posiciona intersubjetivamente. Según White (2004), el lenguaje posiciona a los hablantes y sus textos dentro de la heterogeneidad de posturas sociales y de concepciones del mundo que operan en cualquier cultura. El discurso refleja una determinada realidad social o una posición ideológica. Cada significado dentro de un texto o discurso ocurre en un contexto social, donde podrían haberse elegido otros significados alternativos o contrarios. Obtiene su importancia y su significado social por las relaciones de divergencia o convergencia que establece en relación con esos significados alternativos. Las principales opciones en el sistema de Compromiso se ubican en dos dimensiones contrapuestas: la Monoglosia y la Heteroglosia.

El tercer sistema, Gradación, hace referencia a los valores por medio de los cuales los hablantes gradúan (aumentan o disminuyen) el impacto interpersonal, la fuerza o el volumen de sus emisiones y regulan (desdibujan o agudizan) el foco de sus categorizaciones semánticas. Las dos categorías principales de la Gradación son la Fuerza y el Foco.
La tabla 2 presenta en su conjunto los tres subsistemas de Valoración, con sus respectivas categorías de análisis:

Tabla 2. Sistemas de Valoración

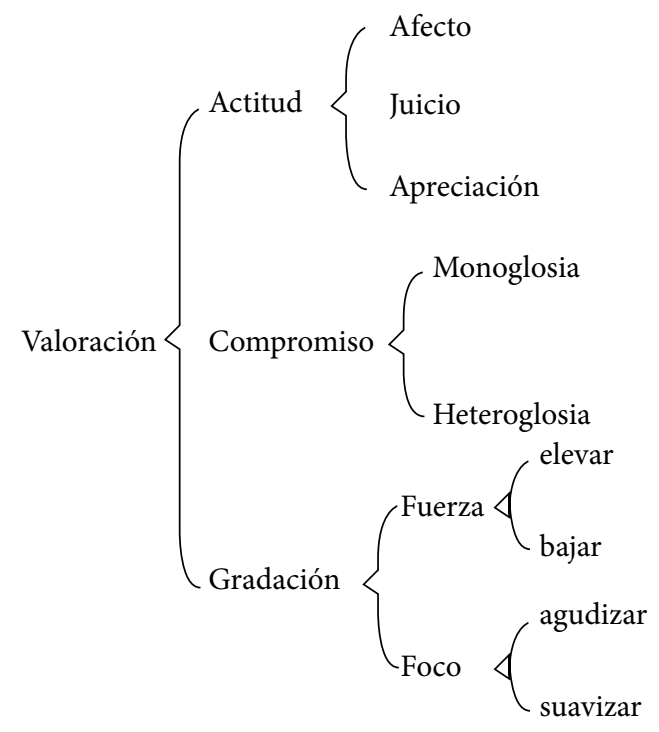

Fuente: Adaptada White, 2005.

En este trabajo, tal como se precisa en el título, por razones de extensión, solo presentamos los recursos para la inscripción de la Actitud en las exposiciones orales de los estudiantes, con los subsistemas de Afecto, Juicio y Apreciación. Queda pendiente para una comunicación futura, el análisis del Compromiso y la Gradación.

\section{Los recursos de la valoración en exposiciones orales}

La recolección de la información se llevó a cabo mediante una ficha de registro de las intervenciones orales de los estudiantes. Antes de pasar al análisis, apuntamos los criterios básicos para la selección del corpus.

En primer lugar se tuvo en cuenta que el corpus estuviera compuesto por la transcripción de las exposiciones hechas por los estudiantes en las sesiones de un componente temático específico. Este lineamiento se corresponde con el objetivo de caracterizar el discurso en su contexto de uso y realizar un análisis con los directos implicados en el proceso. 
Aquí es fundamental tener en cuenta que el discurso oral hace referencia al registro de la palabra hablada en un lugar y en unas circunstancias específicas, con el fin de expresar ideas, sentimientos a otras personas o comunicar conocimientos a un auditorio con el propósito de convencer de unas ideas específicas y, posiblemente, contribuir a la formación de los oyentes. En consecuencia, en el discurso oral a la riqueza del contenido es necesario agregar el manejo adecuado del léxico, la adecuación del lenguaje y el uso de códigos paralingüísticos que refuerzan la presentación de la información.

En segunda instancia, y como consecuencia del primer lineamiento, la focalización del análisis se realizó en los lugares donde aparece directamente la voz del estudiante. Dado que el discurso oral académico es un espacio de interacción entre distintos agentes de producción y trasmisión del saber, en los que actúa una encrucijada de voces, se acude a la exposición del estudiante por lo que este representa en el aula de clase y como principal protagonista en el desarrollo de la investigación sobre oralidad: por un lado, el estudiante es un actor en proceso de construcción de su propio discurso y, por otro, el objetivo de este trabajo es identificar los hábitos y actitudes que asumen los estudiantes en el manejo del discurso oral.

En tercer lugar, la elección del texto base se hizo intencionalmente, acorde con los objetivos planteados para un componente del currículo de los estudiantes. Las grabaciones se realizaron en el marco de la cátedra de Metodología de la Investigación.
Acorde con los contenidos del componente temático, se seleccionó el ensayo "El ajedrez persa" de Carl Sagan (1998), texto que explica la importancia de la notación exponencial y, en general, del conocimiento cuantitativo para conocer y comprender las relaciones de los fenómenos naturales y dar explicación a los problemas de la ciencia y la sociedad.

Como criterio cuarto, la presentación de los estudiantes se realizó con base en tres consignas: primera, presentación del contenido, teniendo en cuenta la importancia de los planteamientos del texto sobre la formación del investigador; segunda, organización de la exposición en introducción, desarrollo y conclusión; y tercera, duración de la puesta en escena de máximo cinco minutos. Coherente con estos lineamientos, para la transcripción se utilizaron fichas en las cuales se incluyó un código o número para cada expositor.

De acuerdo con las categorías establecidas por Martin (2000) y White (2005), presentamos a continuación la inscripción del Afecto en las exposiciones de los estudiantes. Como se puede advertir en nuestro corpus de trabajo, expresiones tales como "Este texto me pareció muy interesante puesto que básicamente se basa en las matemáticas..."(20), ${ }^{5}$ "Esta teoría me pareció muy aprovechativa para mí porque así noté mucho más fácil entender el tema" (20), permiten corroborar que los recursos léxicogramaticales que manifiestan la felicidad e infelicidad, seguridad e inseguridad y la satisfacción e insatisfacción del orador están presentes en los discursos en el aula de clase universitaria (tabla 3 ).

Tabla 3. La expresión del Afecto en las interacciones orales en el aula

\begin{tabular}{|l|l|l|}
\hline \multicolumn{1}{|c|}{ Actitud - Afecto } \\
\hline \multicolumn{1}{|c|}{ Categoría } & \multicolumn{1}{|c|}{ Positivo } & \multicolumn{1}{c|}{ Negativo } \\
\hline $\begin{array}{l}\text { Felicidad/ } \\
\text { Infelicidad }\end{array}$ & $\begin{array}{l}\text { Yo me voy a basar en uno que me interesó mucho que esss } \\
\text { el sida... (2) } \\
\text { El rey quedo fascinado... (1) }\end{array}$ & $\begin{array}{l}\text { ahh...mmm (balbuceo (15) } \\
\text { Ya... listo... (13) }\end{array}$ \\
\hline
\end{tabular}

5 El número al final de las citas encerrado en paréntesis indica el código de la ficha del expositor. 


\begin{tabular}{|c|c|c|}
\hline \multicolumn{3}{|c|}{ Actitud - Afecto } \\
\hline Categoria & Positivo & Negativo \\
\hline $\begin{array}{l}\text { Seguridad/ } \\
\text { Inseguridad }\end{array}$ & $\begin{array}{l}\text { La idea de explicar un tema me pareció muy interesante es que } \\
\text { prácticamente en todo el texto siempre tuvo presente... que } \\
\text { nunca se dejó de lado el crecimiento exponencial (20) } \\
\text { Entonces, finalmente, yo pienso que aparte que el texto es } \\
\text { interesante es muy educativo y muy práctico para educar ya } \\
\text { que yo personalmente descubrí que de simples cosas pode- } \\
\text { mos descubrir pequeños secretos que es bastante interesante } \\
\text { descubrir... (20) }\end{array}$ & $\begin{array}{l}\text { La lectura lleva a darse cuenta que... } \\
\text { hay no profe...no, ya no...o sea... } \\
\text { no...no...ya me morí en serio...(17) } \\
\text { Me gusto...hay no sé...me gus- } \\
\text { to como que las matemáticas es } \\
\text { base... hay... no sé de todas las cien- } \\
\text { cias (18) } \\
\text { Ya no sé que más decir... (18) }\end{array}$ \\
\hline $\begin{array}{l}\text { Satisfacción/ } \\
\text { insatisfacción }\end{array}$ & $\begin{array}{l}\text { Por lo menos yo soy una persona que le tiene fastidio a lo } \\
\text { de las matemáticas... pero pensándolo en lo que nos plantea } \\
\text { el crecimiento exponencial es algo que ponemos en práctica } \\
\text { todos los días... (21) } \\
\text { Yo me voy a basar en uno que me gustó que fue el de... (1) }\end{array}$ & $\begin{array}{l}\text { Hay no... es que cuando la agricul- } \\
\text { tura... ya no... no tienen paa invertir } \\
\text { porque ya el agro ya no da más en- } \\
\text { tonces... (13) } \\
\text { El rey decía que era muy harto... era } \\
\text { una idea muuuy aburrida que le diera } \\
\text { un grano de arroz (1) }\end{array}$ \\
\hline
\end{tabular}

El Afecto puede también clasificarse como autoral (correspondiente a la primera persona) y noautoral (para la segunda y tercera personas). En el primer caso, los expositores en su presentación manifiestan indican cómo han respondido emocionalmente a la persona, cosa, situación o evento que se evalúa y asumen la responsabilidad por esa evaluación. La función retórica más evidente de este uso del Afecto es indicar una posición actitudinal hacia lo que desencadena la emoción y lograr mediante la expresión de una respuesta emocional, establecer una empatía con los interlocutores para que acepten, comprendan, o al menos simpaticen con su reacción emocional, como ocurre en:

Yo voy a empezar por la conclusión que dio el autor eeeen ese ejerciciooo que me parecio muy importante que explica...pues mucchoos conocíamos lo que es el sida... (6)

En el Afecto no autoral, se presentan las emociones a través de los personajes que hacen parte de la temática de la exposición:

El rey quedó tan fascinado con este juego que se trataba de matar al rey oponente... quedó tan fas- cinado que queería darle como una premiación... como un pago... (1)

De igual modo, los expositores manifiestan sentimientos de gratitud y estimación hacia sus compañeros, con frases como locuciones como: "eeehhh, muchas gracias que estén muy bien..." (5), la cual aparece como fórmula de cierre en varias fichas; “Buenos días!, mi nombre es [...] Pertenezco a la clase de metodología de la investigación, en esta oportunidad ehhhhh hoy les voy a hablar del ajedrez persa" (18); "Esta lectura yo creo que cualquier persona la puede entender, no sólo es para personas universitarias sino que a los papás de nosotros se las podemos pasar..." (21).

Otros recursos que manifiestan el Afecto son los adverbios que señalan circunstancias de modo: alegremente, tristemente, lamentablemente, entre otros y también se utilizan adjetivos que expresan emoción (feliz/triste).

En cuanto al Juicio, es decir, las normas sobre cómo deben y no deben comportarse las personas y pautas sociales que se ponen en juego en la interacción, a continuación se presenta algunos ejemplos de las evaluaciones de los estudiantes con base en las categorías de Martin y White, (tabla 4). 
Tabla 4. La expresión del Juicio en las interacciones orales en el aula

\begin{tabular}{|c|c|}
\hline & Actitud - Juicio \\
\hline 1. Estima Social & Positiva (admiración) \\
\hline Normalidad & $\begin{array}{l}\text { Pero como dice mi mamáa usted no lo van a en- } \\
\text { terrar en el ataúd con toda la plata, aaa, la plata } \\
\text { no sirve para nada..entonces ese fue el mayorrrr } \\
\text { problema... (3) } \\
\text { Lo que yo entendí de la lectura fue que... (10) }\end{array}$ \\
\hline Capacidad & $\begin{array}{l}\text { Ehhh ya después el artículo hace evidente algunos } \\
\text { otros casos de crecimiento exponencial... y les } \\
\text { voy hablar de uno que me llamó mucho la aten- } \\
\text { ción... } \\
\text { Y sobre mi opinión opino que pues en mi opinión } \\
\text { personal a mí las matemáticas no me gustaban y } \\
\text { creo que según el libro yo tenía que ver más allá } \\
\text { de lo que no entiendo... (14) }\end{array}$ \\
\hline Tenacidad & $\begin{array}{l}\text { Bueno, ya para empezar al principio hablaba de } \\
\text { un visir que vendió su idea del juego del ajedrez, } \\
\text { pero pues, ninguno de mis compañeros ha expli- } \\
\text { cado qué es un visir en el mundo islámico... haga- } \\
\text { mos de cuenta que es un ministro... (4) }\end{array}$ \\
\hline 2. Sanción Social & Positiva (admiración) \\
\hline Veracidad & $\begin{array}{l}\text { Bueno, en principio me di cuenta que la ciencia } \\
\text { va ligada con las matemáticas y si nosotros no } \\
\text { sabemos de matemáticas no vamos a tener los } \\
\text { resultados obtenidos por una investigación (13) }\end{array}$ \\
\hline Integridad moral & $\begin{array}{l}\text { El autor en ese ejercicio me pareció muy impor- } \\
\text { tante como explica que si conocemos la manera } \\
\text { de las cosas de forma cuantitativa nos va mucho } \\
\text { mejor... Otra cosa que también me gustó muchí- } \\
\text { simo del libro es como el comienzo que él dice } \\
\text { que uuuuyyy las matemáticas son una ciencia per- } \\
\text { fecta que esta no carece de errores ...y que todo } \\
\text { el mundo sepa entender los números (6) }\end{array}$ \\
\hline
\end{tabular}

\section{Negativa (crítica)}

En toodo el mundo hay... no... no... Sí ¿sigo así? Sí sirve la lectura porque uno se da cuenta de los problemas... Lo que más me impactó... (17)

Pues de nada sirve ponernos a decir a todos que todos vamos a morir de sida... y respecto al crecimiento de la población tampoco la solución es decirr no pues no vamos a tener hijos y puuues las personas que queramos tener hijos pues de malas porque no podemos... (21)

El gobierno ha apoyado en los Sisbenes y todo eso regalan los métodos de planificación y cosas así entonces no sé si es más por pereza o por simple machismo... (11)

Pues también me gustó mucho... pues lo que comentaba, o sea, no comprendo muyyy bien las matemáticas yyy también resaltar que quiere como dar a entender (14)

\section{Negativa (critica)}

Entonces hoy no han hablado del papel del dinero en esta situación porque el ser humano eeeh... tomó la peor decisión ...y algunos piensan que la mayor enfermedad de la tierra es el ser humano (3)

Yyyy también la bomba atómica que no es moralmente ética ni nada para nadie... pero nosotros vemos que los países dicen que ¡nooo! Que hagamos bombas nucleares, pero nadie hace nada ahorita (3)
Con respecto a los valores de la Apreciación, mediante los cuales se evalúan artefactos, textos, constructos abstractos como planes y políticas, así como objetos naturales o manufacturados; se ilustran enseguida las categorías encontradas en el corpus (tabla 5). 
Universidad Pedagógica Nacional

Facultad de Humanidades

Tabla 5. La expresión de la Apreciación en las interacciones orales en el aula

\begin{tabular}{|c|c|}
\hline & Apreciación \\
\hline Dimensiones & Positiva \\
\hline $\begin{array}{l}\text { Reacción } \\
\text { Impacto }\end{array}$ & $\begin{array}{l}\text { Lo que más me impactó fue lo de la sobrepoblación por- } \\
\text { que decía que ya en un momento la naturaleza no iba a } \\
\text { dar a abasto. (17) } \\
\text { El juego fue tan llamativo para el rey en su época que } \\
\text { quiso como prrremiarrrr a la persona que lo inventó por } \\
\text { eso le ofreció joyas, le ofreció eeeeehhh, como una parte } \\
\text { de la población, le ofreció bailarinas, le ofreció muchas } \\
\text { cosas pero el sólo quería uuuna parte del trigo.... Por su } \\
\text { buen desempeño a la hora de inventar el ajedrez... (12) }\end{array}$ \\
\hline $\begin{array}{l}\text { Reacción } \\
\text { Calidad }\end{array}$ & $\begin{array}{l}\text { El visir lo creó el juego para algo divertido y el rey le en- } \\
\text { contró mucha gracia porque el juego se basaba en matar } \\
\text { al rey enemigo... (11) } \\
\text { Si el rey hubiera tenido claro el significado de la matemáti- } \\
\text { ca o la aritmética no hubiera accedido fácil a esa petición } \\
\text { que le hizo el visir de darle trigo... (10) }\end{array}$ \\
\hline $\begin{array}{l}\text { Composición } \\
\text { Balance }\end{array}$ & $\begin{array}{l}\text { Sobre el artículo pienso que las matemáticas sirven para } \\
\text { dar respuestas exactas a preguntas que nos hacemos } \\
\text { como por ejemplo de nuestra existencia, de la repro- } \\
\text { ducción biológica, enfermedades de trasmisión sexual, } \\
\text { conocimiento demográfico... mirando estas situaciones } \\
\text { de prontooo hay que generar cambios para que haya un } \\
\text { equilibrio y darse en las partes donde se vean las cosas } \\
\text { como negativas y malas...se debe conocer conocimiento } \\
\text { cuantitativo que es el que nos permite conocer más a } \\
\text { profundidad un tema (8) }\end{array}$ \\
\hline
\end{tabular}

Composición Pienso que las matemáticas sirven para dar respuestas Complejidad exactas a preguntas que nos hacemos... (8)

Pues (la lectura) me pareció una buena forma para enseñarle a uno que todo está relacionado con todo y puess somos relaciones en cadena... (9)

Valuación Entonces finalmente yo pienso que aparte de que el texto es interesado es muy educativo y muyyy práctico... (20)

¿Algo que se llama crecimiento exponencial? ¿Cómo lo materializamos? Simplemente nosotros tenemos una estadística de crecimiento exponencial donde tenemos una unidad y un tiempo... Podemos ver un ejemplo que es sencillo, el de las bacterias... (7)

El rey lo subestimó al visir no vio la capacidad que él tenía para crear ese juego que también buscara una alternativa para salir ganando (85)

Con estos ejemplos se puede evidenciar que las elecciones que hacen los estudiantes para hacer su exposición frente a sus compañeros contienen gran cantidad de recursos para la Actitud, con ellos el orador mantiene el contacto con el auditorio y apela a imágenes que comparte con su círculo de interacción. En estos casos, vale la pena reflexionar hasta dónde se recrea el conocimiento en las intervenciones orales, cómo construye el estudiante su discurso y qué recursos utiliza para diferenciar su voz de la de los autores que recrea en sus exposiciones.

Así mismo, junto al Afecto, el Juicio y la Apreciación que manifiestan los oradores en sus intervenciones, aparecen recursos relacionados con el sistema de Compromiso y de Gradación que enfatizan algunas valoraciones, le dan fuerza a las explicaciones y gradúan en términos de cantidad 
o cualidad los conceptos, los cuales ameritan un análisis aparte.

Con el sistema de Actitud, podemos detallar entonces de qué modo y con qué fines retóricos los estudiantes adoptan posturas actitudinales hacia el contenido experiencial de sus enunciados (los temas), hacia el público (formas con las cuales establece contacto) y cómo se acerca o se distancia de otras voces que operan en sus enunciados y textos. En ese sentido, el estudio de la presencia reiterativa del lenguaje evaluativo en el corpus de referencia brinda, de manera importante, elementos para diseñar una propuesta que permita preparar a los estudiantes para que tengan un mayor conocimiento de los recursos disponibles en el sistema lingüístico y pragmático que les ayuden a mejorar su discurso.

Tal como se advierte en el análisis, en los indicios del Afecto, el Juicio y la Apreciación son evidentes las dificultades que se presentan en las exposiciones de los estudiantes: transmisión incoherente y desorganizada de mensajes, uso desmedido de barbarismos (redundancias, pleonasmos, reiteraciones, retruécanos, muletillas entre otras); deficiencias estructurales de los discursos, dificultades para acompañar la expresión verbal con lenguajes gestuales y corporales adecuados, falencias cognitivas y semánticas a la hora de hacer precisiones, expresar una pregunta e intervenir en el acto pedagógico.

Este tipo de análisis permite reconocer las dificultades que se tienen en la elaboración del discurso oral en el aula: coadyuva a reflexionar no sólo en la preparación del estudiante en los contenidos sino también en los recursos que utiliza para llegar a la audiencia. Luego, conseguir aspectos fundamentales como credibilidad, eficacia e integridad, además de graduar el manejo de la voz, lograr los usos adecuados de las expresiones y ganar la adecuación de la lengua al contexto de situación en exposiciones, disertaciones, participaciones y disentir en intervenciones académicas implica valorar la oralidad como estrategia fundamental en la formación del discurso académico.

\section{A modo de cierre}

La pregunta que guía nuestra investigación se relaciona con la manera de aprovechar la expresión oral como estrategia didáctica en el aula de clase de los universitarios. Para encontrar claves que nos lleven por un camino acertado y nos permitan ofrecer una propuesta que responda a las características reales de los discursos de los universitarios hoy, hemos examinado las manifestaciones orales en un corpus específico. En el sistema de Actitud, con los subsistemas de Afecto, Juicio y Apreciación, hemos advertido las dificultades de los estudiantes para exponer acerca de un tema de ciencia, las inconsistencias que presentan a la hora de recordar datos claves y hacer definiciones.

Así mismo, destacamos ejemplos en los cuales se reiteran palabras, se dan redundancias y simplemente se hacen señalamientos y afirmaciones que no, necesariamente, están sujetas a las temáticas ni a la realidad. Desde este enfoque, consideramos que el trabajo sobre el discurso oral en la universidad puede ayudar en la formación de profesionales con habilidades para confrontar su propio discurso frente al público y desarrollar competencias comunicativas, propositivas, argumentativas e interpretativas que aseguren su mirada crítica y autónoma frente al contexto escolar, familiar y social.

Tal como queda explícito con el análisis discursivo, en las interacciones orales de los estudiantes hace falta corregir errores de dicción, explicar con precisión, exponer con claridad, discutir con argumentos, disentir con evidencias, evaluar con objetividad, cuestionar con rigor y hablar con fluidez.

En este contexto, consideramos que la Teoría de la Valoración, ofrece un marco teórico y metodológico adecuado para analizar los recursos que efectivamente se eligen en las interacciones en el aula para conseguir la explicación, mantener el contacto con los lectores y negociar un espacio de diálogo. El análisis, de hecho, proporciona datos claves para explicar las razones por las cuales resultan más eficaces algunas estrategias de interacción que otras en las dinámicas de enseñanza-aprendizaje e indagar, argumentar y proponer una estrategia didáctica que 
permita integrar el estudio de las funciones, reglas, convenciones, estilo, método, enfoque, roles de los interlocutores, valores y representaciones culturales en las prácticas orales en la universidad, con el fin de fortalecer el discurso académico y profesional de los estudiantes en formación.

Como dice Colombi (2000), una alfabetización disciplinar avanzada requiere saber seleccionar los recursos semióticos adecuados y dominarlos en contextos sociales específicos, acorde con las expectativas de los usuarios, hablantes y oyentes. En este sentido, acceder a la comunidad discursiva disciplinar implica superar el discurso básico, para apropiarse del conocimiento y expresar tal capacidad en la habilidad oral, en este caso, para la estructuración sistemática del discurso, la construcción de argumentos, la destreza en la formulación de las críticas y la disposición para integrar las tecnologías de la información y la comunicación a la función de construir, compartir y socializar el conocimiento.

\section{Referencias}

Andrade, M., y Muñoz, C. (2004). El Taller Crítico: una propuesta de trabajo interactivo. Tabula Rasa 2(200), 251-265.

Asqueta, C., y Muñoz, C. (2001). La fábula del buhonero. Semiótica de la estética mercantil. Bogotá: La Tadeo, Uniminuto Editores.

Aristóteles (2006). Poética (Trad.: Eduardo Sinnot). Buenos Aires: Colihue.

Aristóteles. (2002). Retórica (Trad.: Alberto Bernabé, 4a reimpresión). Madrid: Alianza Editorial.

Bajtin, M. (1979). Estética de la creación verbal. México: Siglo XXI.

Calsamiglia, H., y Tusón, A. (1999). Las cosas del decir. Manual de análisis del discurso. Barcelona: Ariel.

Cisneros-Estupiñán, M. (2012) Cómo elaborar trabajos de grado. Bogotá: Editorial ECOE.

Colombi, C. (2000). En vías del desarrollo del lenguaje académico en español en hablantes nativos de español en los Estados Unidos. En A. Roca (Ed.), Research on Spanish in the United States (pp. 296-309). Somerville, MA: Cascadilla Press.

Halliday, M. A. K. (1994). An introduction to functional grammar. London: Edward Arnold Publisher.
Hood, S., y Martin, J. R. (2005). Invocación de actitudes: El juego de la gradación, de la valoración en el discurso. Signos, Valparaiso, Chile, 58(38), 195-220.

Martin, J. R. (2000). "Beyond exchange: Appraisal systems in English". In: S. Hunston \& G. Thompson (Eds.) Evaluation in text: Authorial stance and the construction of discourse. pp. 142-175Oxford: Oxford University Press,.

Muñoz-Dagua, C. (2014). La Metáfora Interpersonal Léxico-gramatical en la divulgación científica. Bogotá: Universidad Colegio Mayor de Cundinamarca.

Muñoz-Dagua, C., Andrade, M., y Cisneros-Estupiñán, M. (2011). Estrategias de interacción oral en el aula: una didáctica crítica del discurso educativo. Bogotá: Editorial Magisterio.

Ong, W. (1982/1993). Oralidad y escritura. Tecnologías de la palabra. Buenos Aires: Fondo de Cultura Económica.

Sagan, C. (1998). Miles de millones. Pensamientos de vida y muerte en la antesala del milenio. Barcelona: Ediciones B.S.A.

White, P. (2005). An introductory Course in Appaisal Análisis. En: http://www.grammatics.com/ appraisalGuide/Un Framed/IndexOfUFramedGuide.htm 